\title{
Pattern and Variation in the Timing of Aksak Meter: Commentary on Goldberg
}

\author{
RAINER POLAK \\ Cologne University for Music and Dance (Köln, Germany)
}

\begin{abstract}
Daniel Goldberg (2015, this issue) explores relations between timing variations, grouping structure, and musical form in the percussive accompaniment of Balkan folk dance music. A chronometric re-analysis of one of the target article's two audio samples finds a regular metric timing pattern to consistently underlie the variations Goldberg uncovered. Read together, the target article and this commentary demonstrate the complex interplay of a regular timing pattern with several levels of nuanced variation to be performed with fluency, flexibility, and accuracy. This might appear commonplace, but here it is observed in the context of an asymmetric rhythmic mode, non-isochronous beat sequence, and asymmetric metric hierarchy. This context evidently does not represent a constraint of any sort in respect to the rhythmic timing performance, which casts doubts on the deep-seated assumption that metric regularity depends on iso-periodicity and vertical symmetry. This assumption is sometimes explicitly and often implicitly taken as universal; this comment suggests that, on the contrary, it might well be culturally biased.
\end{abstract}

Submitted 2015 March 2; accepted 2015 September 23.

KEYWORDS: timing, asymmetric rhythm, non-isochronous meter

MUSIC theorist Daniel Goldberg (2015, this issue) studies the timing of percussive rhythms in two recorded live performances from south-eastern Europe. In one recording, Macedonian singer Muzafer Bizlim taps along his own singing; in the other, Bulgarian drummer Mitko Popov plays in an instrumental ensemble accompanying song and dance. Both performances share that their rhythmic modes involve metric cycles of two unequal beat durations (long vs. short), of the type conventionally addressed as aksak, or asymmetric, or non-isochronous meter (Brăiloiu, 1984; Cler, 1994; 1997; Arom, 2004; Moelants, 2006; London, 2012). The metric cycle involves three beats (long-short-short) and seven subdivisions, which are grouped by the beats into units of 3-2-2 (x..x.x.).

The study is based on chronometric timing analysis and informed by music analytic and ethnographic insights. Its focus is on exploring differences - variations and flexibilities - in the timing data, and suggesting hypotheses about possible influences of other aspects of musical structure and performance on the observed timing differences. The article is particularly welcome as a contribution to performance timing studies in aksak-based rhythms (see Cler, 1997; Moelants, 2006) and thus to the growing body of chronometric research on genres beyond European art music and jazz.[1]

\section{INFLUENCE AND INTERDEPENDENCE OF TIMING, GROUPING, AND FORM}

Goldberg's thinking follows the mainstream of chronometric timing research in that it asks for influences of other musical factors (other aspects of the musical structure and performance) on timing, not vice-versa. Recently, however, musicologists, music theorists, and ethnomusicologists have begun to empirically examine also the constitution (not only expression) of musical style and meaning (Leech-Wilkinson, 2009; 2012), metric structure (Polak, 2010), and grouping structure (Ohriner, 2012) in and through musical performance, including performance timings. Such views gain relevance and support as music psychology no longer conceives of expressivity (e.g., expressive timing) as a deviation from scores or allegedly universal cognitive principles (e.g., isochrony and simple integer ratios as the basis for rhythmic categories), but from local or stylistically conventional norms of performance timings (Honing, 2013; Fabian et al., 2014). 
That said, Goldberg's study compellingly argues for the influence of various levels of melodic grouping and musical form on the timing of the percussion part. It thus supports a body of research that over the past decade has highlighted the significance and complexities of such relations (for examples from the field of swing timing research in jazz music, see Benadon, 2006; Benadon, 2009; Mermikides, 2010; Butterfield, 2011), superseding unrealistically dichotomic earlier conceptualizations of structure versus "expressive" or "participatory" timing (cf. Clarke, 1985; 1987; Keil, 1987; 1995).

The relationships between timing, melodic grouping and musical form are complex in that they occur at the same time and are superimposed (and perhaps interrelated) to one another. Such complexity makes Goldberg skeptical about efforts to isolate a single factor as the basis for the performance timings he observed. This has implications for the possible experimental testing of Goldberg's hypotheses, and of hypotheses extracted from performance timing studies in general. The design of stimuli for evaluation of timing differences in listener tests needs to be carried out with utmost care, striving for ecological validity by trying to reflect the complex characteristics of the performed music (see Kilchenmann \& Senn, 2015 for the example of groove research). Manipulating single aspects-e.g., timing pattern structure or proportions, or ensemble asynchrony patterns - without reflecting the embeddedness and possible dependencies of these from one another and from other aspects of the music as performed might bear risks of distorting the perceptual effects of these single aspects.

\section{TIMING AND ENSEMBLE DYNAMICS}

Next to influences of melodic grouping and musical form, Goldberg also discusses the possible influences of the interaction and coordination among ensemble members on the timing. He convincingly argues that certain timing variations are of smaller degree when the percussionist in Audio Sample 2 serves to accompany song and dance rather than when he produces more complex rhythmic elaborations. By contrast, the hypothesis that the percussionist in situations of more pronounced timing variations takes on a leadership role in the ensemble, if generally plausible, is somewhat weak in terms of empirical backing. Goldberg's approach, i.e., measuring the timing of individual performers, meets a limit here; a productive evaluation of ensemble dynamics based on timing would require extracting data for all (in the best case) or at least two members of the quintet ensemble and then analyze not just the time series of individual parts, but the correlations of phase and period correction between parts (e.g., Glowinski et al., 2012; Timmers et al., 2014).

\section{MAIN CONTRIBUTION OF THIS COMMENTARY}

To test the validity of Goldberg's empirical findings, I carried out a chronometric re-analysis of one of the two recordings in the target study. In the performance of "Bešli i čaj tele" (Goldberg's Audio sample 1), singer Muzafer Bizlim accompanies himself by tapping out an ostinato rhythm of five basic strokes plus several ornamental grace notes, spread over a metric cycle of three uneven beats (long-short-short) and seven subdivisions (3-2-2), often transcribed in staff notation as 7/8 (see Goldberg's Figure 1 and 3). Goldberg's analysis for unspecified reasons covers only three onsets of the five-stroke pattern, those which constitute the metric beats. This decision is not implausible, at least given the assumption is true that rhythm in aksak meter is beat-based, as speaks from that dancing to this music relies to and embodies these beat patterns to a great extent (Rice, 1994, 73; 98-103). However, it results in a loss of information as it omits two of five strokes of a percussive ostinato. In resonance with the explorative thrust of the target study, I thus decided to refocus the chronometric analysis by one level, from main beat to subdivisions, thus accounting for the timing of the complete pattern of basic strokes (Figure 1).

In the following, I will first review Goldberg's suggestions on relations of the percussion timing with the melodic grouping and musical form of the song and then propose, based on my re-analysis, a possible relationship of the timing with meter. I will finally discuss implications of Goldberg's and my own analyses for theoretical frameworks of rhythm performance and perception. 


\begin{tabular}{|c|c|c|c|c|c|c|}
\hline \hline 1 & & & 2 & & 3 & \\
\hline 1.1 & 1.2 & 1.3 & 2.1 & 2.2 & 3.1 & 3.2 \\
\hline \hline $\mathrm{x}$ & & & $\mathrm{x}$ & & $\mathrm{x}$ & \\
\hline $\mathrm{x}$ & & $\mathrm{x}$ & $\mathrm{x}$ & & $\mathrm{x}$ & $\mathrm{x}$ \\
\hline \hline
\end{tabular}

beats in the metric cycle (bar)

beat subdivisions in the metric cycle

onbeat strokes measured by Goldberg

full stroke pattern measured in the re-analysis

Fig. 1. Strokes measured in target article (Goldberg 2015) and re-analysis (this commentary)

\section{Timing, grouping, and form in Muzafer Bizlim's "Bešli i čaj tele"}

Goldberg finds timing variations on three different levels, all of which emerge in my re-analysis, thus verifying the measurements and calculations presented in the target article.

First, the overall tempo, as measurable in the interonset intervals (IOIs) between downbeats of bars, decelerates at the beginning and ending of each of the six verses of the song (see Goldberg's Figure 5). The timing thus clearly relates to these basic building blocks of musical form.

Secondly, there is a change in the timing ratio of the percussion strokes across bars. This change runs parallel to the four-bar melodic phrases as well as to eventual two-bar subphrases of the song, which are segmented melodically, rhythmically by a rest, and by the singer breathing during that rest. Goldberg finds the stroke on Beat 3 (the last of the three beats in the bar) to be lengthened at each segmentation of (sub-)phrases and suggests that this might be expressive of the segmentation. This may appear somewhat foreign to listeners and readers of the literature on phrase-final or group-final lengthening [2] in European art music performance and in Romantic piano music in particular (see, for instance, Todd, 1985; Repp, 1997; Ohriner, 2012), where the rubato occurs in the form of wave-like, phrase-arching contours of local tempo change. In the Macedonian folk song under study, only one beat in a specific metric position is lengthened, while the surrounding beats remain stable or even are slightly shortened. Nonetheless, Goldberg seems right to draw the comparison, since a lengthening of Beat 3 clearly occurs on the endings of groups (4-bar phrases and 2-bar sub-phrases) and the resulting delay of the subsequent downbeat indeed does emphasize the group boundaries.[3]

My re-analysis of Muzafer Bizlim's tapping uncovers a small, yet interesting detail of this timing variation. The lengthening of Beat 3 at group boundaries is effected not by extending the beat duration as scaled over both subdivisions. Bizlim lets the onbeat duration (Subdivision 3.1) remain almost unchanged, with a mean difference of less than $10 \mathrm{~ms}$. By contrast, the variation of the offbeat duration (Subdivision 3.2) across bars is far more marked, with mean differences above $30 \mathrm{~ms}$ (see Figure 2). The lengthening thus is largely effected in the IOI between the final stroke in the measure (Beat 3.2) and the following downbeat (next cycle Beat 1.1). This further supports the view, which can already be read from Goldberg's analysis, that the group-final lengthening in the tapping is accomplished as a hard phase reset of the metric cycle at the downbeat. 


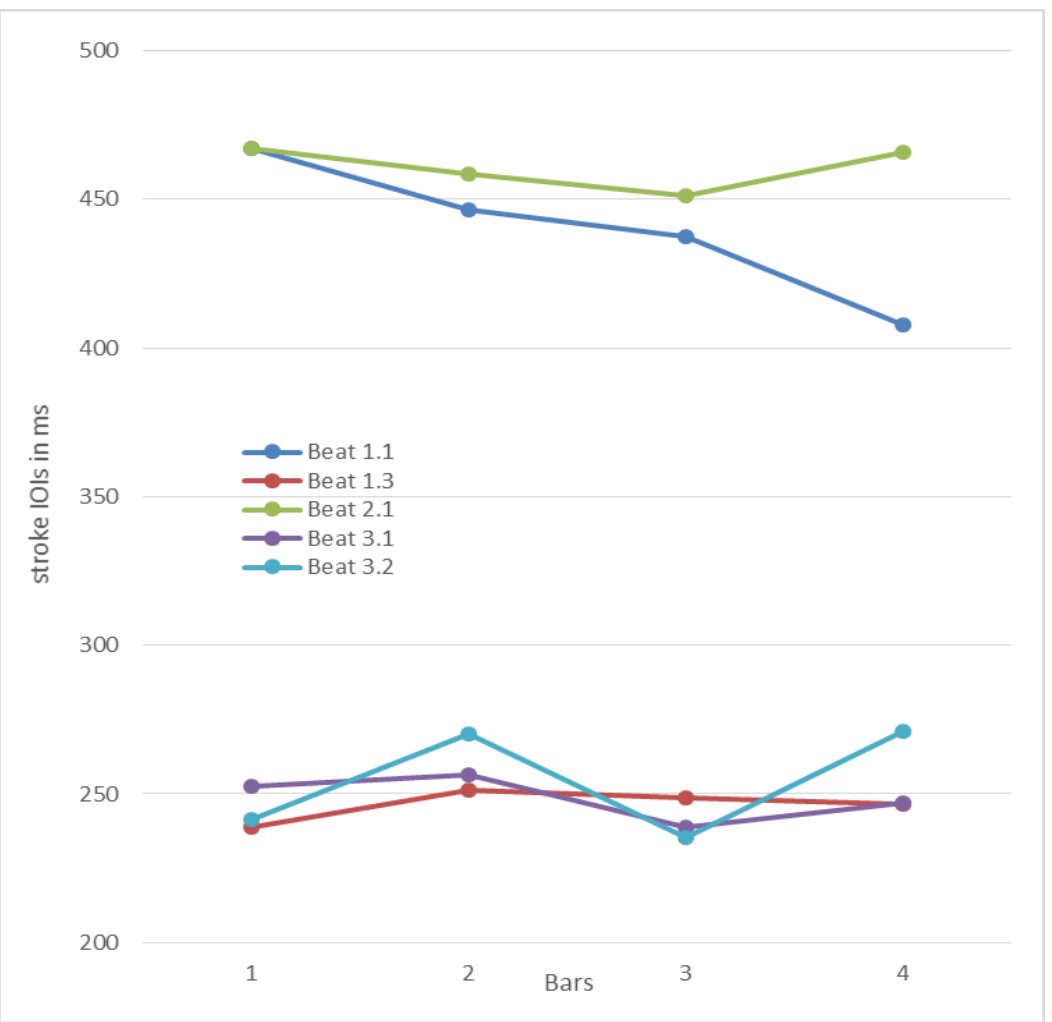

Fig. 2. Fluctuation of mean stroke IOIs over Phrase A (one of two basic phrases of the song), which extends over four bars and is segmented into two two-bar subphrases

Thirdly, Goldberg's Figure 4 shows that, irrespective of the phrase-related fluctuation of IOIs across bars, Beat 3 in every bar is longer than Beat 2; the mean ratio of the three beats is approximately 3:2:2.2 (not 3:2:2). Goldberg suggests that this, too, might represent a case of group-final lengthening. However, this hypothesis does not explain why phrase and sub-phrase endings that occur in Bars 2 and 4 should have this effect in Bars 1 and 3, too. An alternative suggestion Goldberg puts forth is that a stable timing template might underlie the rhythm performance independently of grouping and form.

This latter view obtains support from my re-analysis of the five-stroke ostinato. The rhythmic figure consists of a sequence of two durational categories, a short one which spans one subdivision (an eighth note as in 7/8 notation) and a long one that extends over two subdivisions (a quarter note); the sequence is long-short-long-short-short. The re-analysis finds that the strokes on Beats 1.3 and 3.2 (not covered in Goldberg's analysis) are timed in a way that the two rhythmic categories (long and short) in each of their respective instantiations emerge as of near identical duration (see Figure 3). This is quite surprising; given that the beat sequence is timed according to a ratio of $\sim 3: 2: 2.2$, a regular timing pattern for the five- stroke figure within the three-beat cycle was not easily foreseeable. 


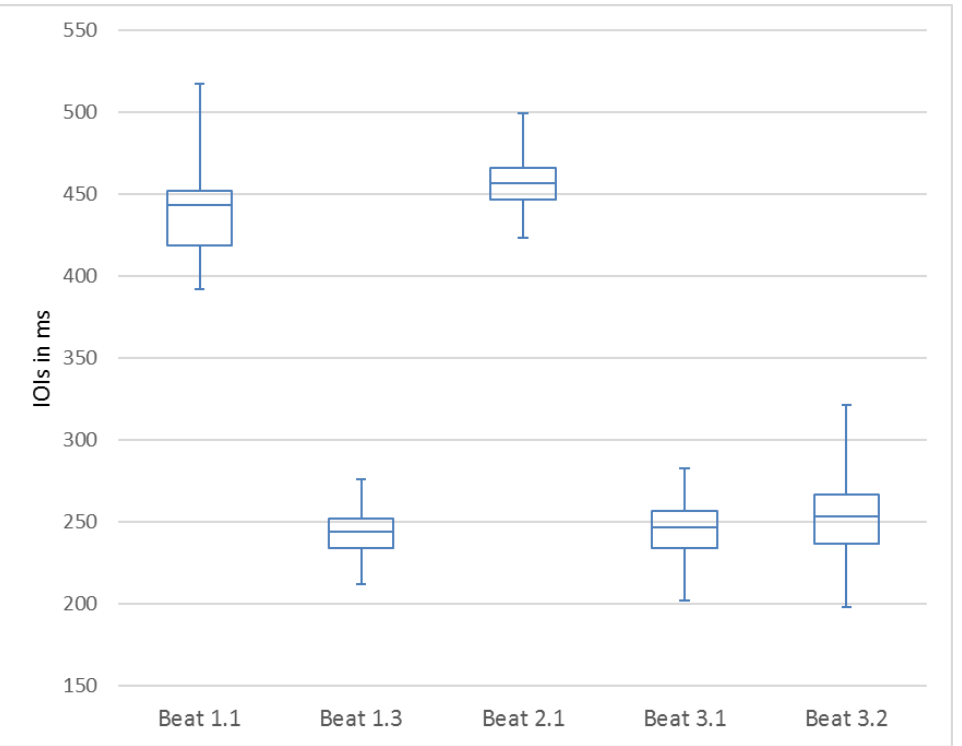

Fig. 3. Boxplot of the timing of the five strokes of the basic ostinato over the whole performance.

The proportional timing pattern for the long-short-long-short-short ostinato does not depend on grouping structure; it holds for both of the two phrases the song consists of. Note the relatively higher variability of Beat 1.1 and Beat 3.2 in Figure 3 reflects the marking of the higher level phrase rhythm in these two metric positions, discussed above. Normalizing the tempo fluctuations and giving the timings as percentages of the local bar duration again shows an amazing degree of regularity of the timing pattern (see Figure 4).

\begin{tabular}{|c|c|c|c|c|c|c|}
\hline \hline 1 & & & 2 & & 3 & \\
\hline 1.1 & 1.2 & 1.3 & 2.1 & 2.2 & 3.1 & 3.2 \\
\hline \hline $\mathrm{x}$ & & $\mathrm{x}$ & $\mathrm{x}$ & & $\mathrm{x}$ & $\mathrm{x}$ \\
\hline 27 & & 15 & 28 & & 15 & 15 \\
\hline 1 & & 1 & 1 & & 1 & 1 \\
\hline
\end{tabular}

three beats in the metric cycle (bar)

seven beat subdivisions in the metric cycle

full stroke pattern measured in the re-analysis

percentages of bar duration

standard deviations in percent

Fig. 4. Timing ratio of the basic five-stroke pattern in percentages of bar duration

The stable proportion of long and short durations has a mean ratio (long:short) of $\sim 1.8$, which is reminiscent of various reports on systematic smoothening of rhythmic contrast in uneven two-note and three-note groups. In Swedish folk dance music, two-note rhythmic cells often are performed as "broad" pairs, with a ratio of about 1.75 rather than 2.0 (Gabrielsson et al., 1983). Repp et al. (2011; 2012) have shown experimentally that the prototypical center, or "attractor ratio," for uneven two-note rhythm performance does not always lie around 2.0, but more often lies between 1.75 and 1.9. African-American musicians frequently "spread" uneven three-note-groups, such as two 16th plus an 8th note (Iyer, 2002). Macedonian singer Muzafer Bizlim's timing pattern of the five-stroke ostinato might well speak of the same tendency to smoothen rhythmic contrast.

In any case, the timing pattern of the five-stroke ostinato, by using equal durational proportions for each instantiation of the two rhythmic categories across the pattern, shows an aspect of regularity which is not easily explainable from a beat-based perspective. It seems plausible that the regular timing pattern for the five-stroke ostinato pattern drives the irregular timing of the three-stroke beat sequence, rather than vice-versa. And what is more, the regular, yet irrational timing pattern of the ostinato (not based on simple integer ratio) is not at all comprehensible from the perspective of the many theories that assume metric regularity to require iso-periodicity of metric pulsation. 


\section{Timing, rhythm, and meter}

The timing differences Goldberg's article focuses are mostly small, as he points out, and in some cases close to unperceivable. Underlying these nuanced fluctuations and variations is a stable timing pattern, as the above re-analysis of the five-stroke ostinato helped to point out. I dedicate the remainder of this commentary to discussing some implications of this timing pattern and its variations to the conceptualization of temporal frameworks for rhythm production and perception.

From the perspective of classical concepts of empirical rhythm research, such as systematic variation of duration (Bengtsson et al., 1972; Bengtsson, 1975), expressive timing (Clarke, 1985;1987), and participatory discrepancies (Keil, 1987; 1995), the lively rhythmical timings in the analyzed audio recording would appear to represent deviations from the integer ratios of rhythmic structure as based on an underlying isochronous beat subdivision. These deviations would follow a common pattern in so far as the performed strokes all slightly precede the expectations of the metronomic grid, presuming that Beat 1.1 represents the common reference point of metric perception and performance timing (see Figure 6). This "negative asynchrony" varies, however; it is small on Beats 1.3 and 3.1, with a mean discrepancy of $\sim 30 \mathrm{~ms}$, and even smaller, probably close to unperceivable on Beats 2.1 and 3.2, with a mean discrepancy of $\sim 20 \mathrm{~ms}$. The performance of the alleged deviations from the isochronous subdivision thus would appear to represent a delicate task.

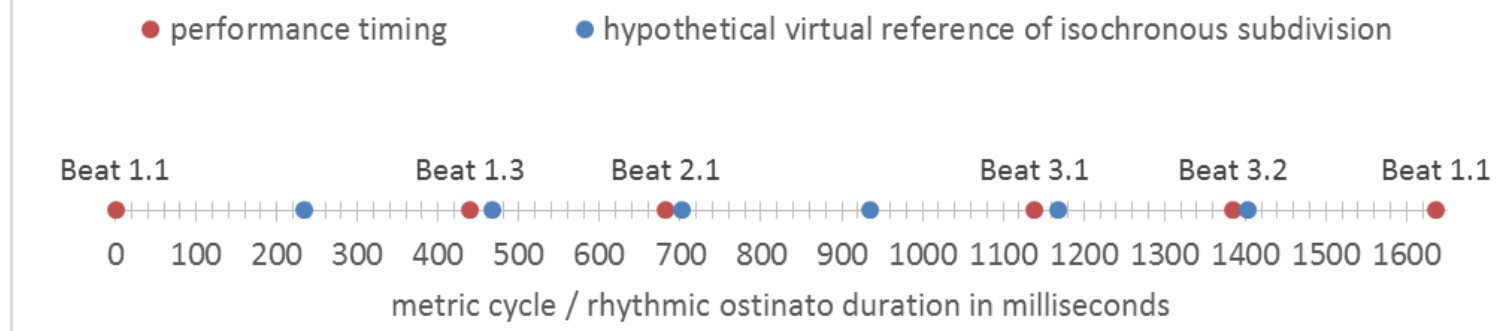

Fig. 6. Mean performance timing of the five-stroke accompaniment and (hypothetical) virtual reference of isochronous subdivision pulse. Beat 1.1 is assumed as common starting point.

The cognitive separation of perceived temporal information as either categorical (aligning strokes to the metric grid) versus expressive (assessing the differences between strokes and grid), as assumed in the classical models of performance timing, would have to deal at the same time with the various influences of melodic grouping and musical form on the local tempo, the dual task performance of a singer tapping along himself and, more generally, the condition that the basic beat sequence is non-isochronous (long-shortshort). Taken together, all this would amount to an extremely complex task. Note that the sheer fact of an asymmetric rhythm set in a non-isochronous beat sequence already, by itself, is a "mystery" (Large, 2008, 222 ) to the psychology of pulse and meter perception. Contemporary concepts of temporal frameworks for rhythm perception and production-from metric projection (Hasty 1997) to metric pulse and accent hierarchy (Yeston, 1976; Lerdahl \& Jackendoff, 1983), beat induction (Desain \& Honing, 1999; Honing, 2012) and beat-based internal clock models (Povel, 1984; Povel \& Essens, 1985) to dynamic attending and neural oscillation theory (Large \& Jones, 1999; Snyder \& Large, 2005) - all theorize the casting forward, from present experience of just-past duration into immediate future, of nominally iso-periodic durations. All these theories, which have been prominent and influential in the music theory and music psychology of rhythm and meter over the past three decades, do not even try to account for the projection of nonisochronous, categorically uneven time-intervals. They equate, a priori, metric regularity with isochrony. In suspiciously stark contrast, however, the majority of timing studies of musics other than Euro-American art or popular music (cf. Endnote 1) demonstrated fundamentally non-isochronous temporal frameworks and/or non-integer rhythmic proportions.

Obviously, thinking in the classical models of music psychology and music theory hardly allows one to conceive of temporal regularity beyond isochrony and small integer ratio, which, however, evidently does exist. From the classical, "Western" perspective, non-isochronous beat sequences necessarily appear 
to be irregular, and typically are classified as exceptional, if considered at all. However, how can Muzafer Bizlim perform all the complex timing tasks specified above - smoothening contrast in the rhythmic cell, group-final lengthening for phrase segmentation, tempo rubato expressing verse-based musical formwhen even his basic rhythmic mode is "irregular" and "deviating" from still another underlying framework? And all this while tapping along his own singing, in what is no more than a simple band-aid for not having a proper percussionist at his disposal? With enough ease to embellish the basic rhythm with virtuosic ornaments?

Enkindled by the ethnographic observation that encultured performers and listeners do not perceive aksak meters as "irregular" or otherwise categorically different from "normal" ones (Rice, 2000a; 2000b),[4] and fuelled by the complex relationship of patterned regularity and flexible variation in the timing performance studied by Goldberg and above, suspicion falls on that there might be something deeply wrong with the axiomatic assumptions that rhythmic structure universally relies on small integer ratio and metric structure naturally depends on isochrony. There is experimental evidence that to Bulgarian, Turkish, and Indian, but not to American listeners, non-isochronous meters of the aksak type appear as easily accessible and natural as isochronous ones (Hannon, 2009; Hannon et al., 2012a; 2012b; Ullal-Gupta et al., 2014). Obviously, unevenness to some extent can be metrically integrated without detracting from regularity, by people who grow up in a music-cultural environment where asymmetric rhythms implying non-isochronous beat sequences are performed as frequently and normally as rhythms that lend themselves to isochronous beats; exposure and culturally situated statistical learning in this respect appear to be decisive.

Some theorists of non-isochronous meter hypothesize that the inherent mathematical disadvantage of non-isochrony on one metric level must be balanced, in a sort of cognitive work-around, by isochrony on some neighboring level, e.g., on the level of a common slow pulse (Kvifte, 2007) or a fast density referent (London, 2012, chapt. 8). In the case of aksak meter, the subdivision level suggests itself as a possibly fundamental frame of metric reference (Arom, 2004). However, this would seem to require that the metric subpulse really is approximately isochronous, which appears to be true in some cases of aksak rhythm,[5] but not in all, as our example demonstrates. Goldberg (2015) mentions that non-integer ratios are more generally characteristic of regional styles from Macedonia, in contrast to, for instance, Bulgaria. Moreover, the conception of the fast subdivision as elementary reference level runs counter to the common sense of most metric theories, including Goldberg's view of aksak meter, that a beat (pulse, tactus) at the medium level of the metric hierarchy (not the beat subdivision close to the rhythmic surface) represents the main metric reference. Finally, many performances of aksak meter take place at tempos where the subpulse is too fast to serve as the beat (Moelants, 2006), or at least will loose in its power to provide metric orientation.

In sum, the "mainstream" or "classical" approach to timing, rhythm, and meter, which is based on the axioms of isochrony and small integer ratios, cannot explain how the basic beat sequence in aksak rhythms represents a stable metric framework and thus can hardly explain how such a "limping" beat would provide enough orientation for understanding, as "deviations," the complex timing patterns, fluctuations and variations described in the target article and above. A radically different approach to conceptualizing these timings is required. One such approach is to conceive of the timings not as deviations, but as the very context in which the metric framework is constituted through perceiving, attending to, and memorizing prototypical mean values, ranges and patterns of variation, and flexibilities around them. From this view, the timing patterns given in Figures 3 and 4 (see above) could hypothetically represent temporal templates in their own right, or metric timing patterns (Kvifte, 2007; London, 2012). The regularity of timing pattern found in the five-stroke ostinato can be read as supporting this hypothesis; at least, its periodic recurrence in each metric cycle provides an environment the invariants of which presumably represent an ideal framework for the establishment of metric templates within performance.

Such thinking appears realistic from culturally informed, ethnographic perspectives. It would dramatically reduce the otherwise abundantly complex cognitive task of processing multi-layered expressive timing "deviations" of an already "deviant" rhythmic timing pattern (e.g., the 1.8 ratio in the five-stroke ostinato) performed in the context of a framework which yet again is "deviant" (as it is nonisochronous). On the other hand, the concept of asymmetric metric hierarchies or metric performance templates points to other large gaps in contemporary theories of temporal organization: It would force one to conceive of the possibility of non-iso-periodic pulse, that is, of categorically unequal durations that are nonetheless perceived to be regular and experienced as pulsating. Moreover, it would imply to conceive of either asymmetric yet nonetheless nested hierarchies of two or more layers of such non-isochronous pulse 
streams, or of the metric projection of wholesale metric cycles as fully integrated (non-hierarchical) temporal templates.

\section{CONCLUSION}

Goldberg empirically explored timing variations in the percussive accompaniment of recordings of southeastern European folk dance music and suggested plausible hypotheses about their complex relations to grouping structure and musical form. A chronometric re-analysis of one of the target article's two audio samples found a surprisingly regular timing pattern in the rhythmic ostinato to underlie the variations Goldberg uncovered; this performance pattern recurs in each metric cycle and possibly constitutes a temporal template, or metric timing pattern.

Read together, the target article and this commentary demonstrate the complex interplay of a regular timing pattern with several levels of nuanced timing variations, and that these variations are performed with fluency, flexibility, and precision. In other musical contexts this observation might appear commonplace, but here it is observed in the context of an asymmetric rhythm, non-isochronous beat sequence, and asymmetric metric hierarchy. This context evidently does not represent a constraint of any sort in respect to the musical timing performance, which casts doubts on the deep-seated assumption that metric regularity requires, or at least strongly privileges, iso-periodicity and vertical symmetry. This assumption is sometimes explicitly and often implicitly taken as universal; this comment suggests that, on the contrary, it might well be culturally biased.

\section{NOTES}

[1] Next to European art music and jazz, samba from Brazil (Gerischer, 2003; 2006; Lindsay \& Nordquist, 2007; Guillot, 2011; Nevada et al., 2011; Haugen \& Godøy, 2014) and folk dance music from Scandinavia (Bengtsson, 1975; Gabrielsson et al., 1983; Kvifte, 2007; Johansson, 2009; Johansson, 2010; Haugen, 2014) stand out as forms of music that have attracted the interest of more than singular performance timing studies. By contrast, research on the timing of musics from, for instance, the African continent and the Middle East is scarce and fragmentary (Elsner, 1990; During, 1997; Polak, 2010; Jankowsky, 2013; Polak \& London, 2014). Powerful efforts towards representing cultural diversity in empirical rhythm research are collected in a special issue of Cahiers d'Ethnomusicologie $\left(\mathrm{N}^{\circ} 10 ; 1997\right)$ and in a volume edited by Clayton et al. (2013).

[2] Goldberg follows Ohriner (2012) in speaking of "group-final" lengthening instead of the more common "phrase-final" lengthening.

[3] Listen to Goldberg's Audio Sample 1; the first two instances of group-final lengthening in Phrase A appear in Verse 1, Phrase 1, end of Bars 2 (00:09) and 4 (00:13).

[4] Rice (2000b) asserts that the introduction of the concept of "irregular" meter to South-East-European folk music, and speculative theories that these might have been historically and/or structurally deduced as deviations from regular meters, goes back to middle-European thinking. On the analogous argument that encultured listeners do not perceive swing-based meters (non-isochronous metric beat subdivision patterns) as irregular, see Polak (2010) and Polak and London (2014).

[5] Approximately integer $(\sim 3: 2)$ proportions for the beats, and thus the possibility of nominally isochronous subdivisions, are found by Cler (1997, par. 58) in an example of aksak rhythm from Turkey.

\section{REFERENCES}

Arom, S. (2004). L'aksak: Principes et typologie. Cahiers de Musiques Traditionnelles, 17, 11-48. 
Benadon, F. (2006). Slicing the beat: Jazz eighth-notes as expressive microrhythm. Ethnomusicology, 50(1), 73-98.

Benadon, F. (2009). Time warps in early jazz. Music Theory Spectrum, 31(1), 1-25.

Bengtsson, I., Tove, P.-A., \& Thorsén, S.-M. (1972). Sound analysis equipment and rhythm research ideas at the Institute of Musicology in Uppsala. In E. Stockmann (Ed.), Bericht über die 3. Internationale Arbeitstagung der Study Group on Folk Musical Instruments des International Folk Music Council in Stockholm 1969 (pp. 53-76). Stockholm: Musikhistoriska Museet.

Bengtsson, I. (1975). Empirische Rhyhmusforschung in Uppsala. In C. Floros, H. J. Marx, and P. Petersen (Eds.), Hamburger Jahrbuch für Musikwissenschaft (pp. 195-220). Hamburg: Karl Dieter Wagner.

Brăiloiu, C. (1984). Aksak rhythm. In C. Brăiloiu (\& A. L. Lloyd, translation), Problems of Ethnomusicology (pp. 133-67). Cambridge: Cambridge University Press.

Butterfield, M. W. (2011) Why do jazz musicians swing their eighth notes? Music Theory Spectrum, 33(1), $3-26$.

Clarke, E. F. (1985). Structure and expression in rhythmic performance. In P. Howell, I. Cross, \& R. West (Eds.), Musical structure and cognition (pp. 209-236). London: Academic Press.

Clarke, E. F. (1987). Categorical rhythm perception: An ecological perspective. In A. Gabrielsson (ed.), Action and Perception in Rhythm and Music (pp. 19-34). Stockholm: Royal Swedish Academy of Music.

Clayton, M., Dueck, B., \& Leante, L. (Eds.). (2013). Experience and Meaning in Music Performance. Oxford: Oxford University Press.

Cler, J. (1997). Aksak: les catastrophes d'un modèle. Cahiers de Musiques Traditionnelles, 10, 60-80.

Cler, J. (1994). Pour une théorie de l'aksak. Revue de Musicology, 82, 181-210.

Desain, P. \& Honing, H. (1999). Computational models of beat induction: the rule-based approach. Journal of New Music Research, 28, 29-42.

During, J. (1997). Rythmes ovoïdes et quadrature du cycle. Cahiers de Musiques Traditionnelles, 10, 1736.

Elsner, J. (1990). Der Rhythmus Insiraf: Zum Problem quantitativer Rhythmik. In O. Elschek (Ed.), Rhythmik und Metrik in traditionellen Musikkulturen (pp. 239-49). Bratislava: VEDA.

Fabian, D., Timmers, R., \& Schubert, E. (Eds.). (2014). Expressiveness in music performance: Empirical approaches across styles and cultures. Oxford: Oxford University Press.

Gabrielsson, A., Bengtsson, I., \& Gabrielsson, B. (1983). Performance of musical rhythm in 3/4 and 6/8 meter. Scandinavian Journal of Psychology, 24(1), 193-213.

Gerischer, C. (2003). O Suingue Baiano. Mikrorhythmische Phänomene in Baianischer Perkussion. Frankfurt am Main: Peter Lang.

Gerischer, C. (2006). Suingue Baiano: Rhythmic Feeling and Microrhythmic Phenomena in Brazilian Percussion. Ethnomusicology, 50(1), 99-119.

Glowinski, D., Badino, L., Ausilio, A., Camurri, A., \& Fadiga, L. (2012). Analysis of leadership in a string quartet. In Third International Workshop on Social Behaviour in Music at ACM ICMI 2012. 
Goldberg, D. (2015). Timing variations in two Balkan percussion performances. Empirical Musicology Review, 10(4), 305-328.

Guillot, G. (2011). Des objets musicaux implicites à leur didactisation formelle exogène : transposition didactique interne du suingue brasileiro en France. Unpublished doctoral dissertation, Université de Paris Sorbonne, Paris, France.

Hannon, E. (2009). Musical enculturation: How young listeners construct musical knowledge through perceptual experience. In S. Johnson (Ed.) Neoconstructivism: The New Science of Cognitive Development (pp. 132-56). Oxford: Oxford University Press.

Hannon, E. E., Soley, G., \& Ullal, S. (2012a). Familiarity overrides complexity in rhythm perception: A cross-cultural comparison of American and Turkish listeners. Journal of Experimental Psychology: Human Perception and Performance, 38(3), 543-48.

Hannon, E. E., der Nederlanden, V. B., Christina, M., \& Tichko, P. (2012b). Effects of perceptual experience on children's and adults' perception of unfamiliar rhythms. Annals of the New York Academy of Sciences, 1252(1), 92-99.

Hasty, C. (1997). Meter as rhythm. Oxford, Oxford University Press.

Haugen, M. R., \& Godøy, R. I. (2014). Rhythmical Structures in Music and Body Movement in Samba Performance. In Moo Kyoung Song (Ed.) Proceedings of the ICMPC-APSCOM 2014 Joint Conference (pp. 46-52). Yonsei University.

Haugen, M. R. (2014). Studying Rhythmical Structures in Norwegian Folk Music and Dance Using Motion Capture Technology: A Case Study of Norwegian Telespringar. Musikk og Tradisjon 28, 27-52.

Honing, H. (2012). Without it no music: beat induction as a fundamental musical trait. Annals of the New York Academy of Sciences, 1252, 85-91.

Honing, H. (2013). The structure and interpretation of rhythm in music. In D. Deutsch (Ed.), Psychology of Music, third edition (pp. 369-404). London: Academic Press.

Iyer, V. (2002). Embodied Mind, Situated Cognition, and Expressive Microtiming in African-American Music. Music Perception, 19(3), 387-414.

Jankowsky, R. C. (2013). Rhythmic Elasticity, Metric Ambiguity, and Ritual Teleology in Tunisian Stambeli. Analytical Approaches to World Music, 3(1).

Johansson, M. (2009). Rhythm into style. Studying asymmetrical grooves in Norwegian folk music. Unpublished doctoral dissertation, University of Oslo, Norway.

Johansson, M. (2010). The concept of rhythmic tolerance: Examining flexible grooves in Scandinavian folk fiddling. In A. Danielsen (Ed.), Musical Rhythm in the Age of Digital Reproduction (pp. 69-83). Ashgate Publishing.

Keil, C. (1987). Participatory discrepancies and the power of music. Cultural Anthropology, 2(3), 275-83.

Keil, C. (1995). The Theory of Participatory Discrepancies: A Progress Report. Ethnomusicology, 39(1), 120.

Kilchenmann, L., \& Senn, O. (2015). Microtiming in Swing and Funk affects the body movement behavior of music expert listeners. Frontiers in Psychology, 6. 
Kvifte, T. (2004). Description of grooves and syntax/process dialectics. Studia musicologica norvegica, 30, $554-77$.

Kvifte, T. (2007). Categories and timing. On the perception of meter. Ethnomusicology, 51(1), 64-84.

Large, E. W. (2008). Resonating to musical rhythm: theory and experiment. In S. Grondin (Ed.), Psychology of time (pp. 189-232). Bingley: Emerald Group Publishing.

Large, E. W., \& Jones, M. R. (1999). The dynamics of attending: How people track time-varying events. Psychological Review, 106(1), 119.

Leech-Wilkinson, D. (2012). Compositions, scores, performances, meanings. Music Theory Online, 18(1).

Leech-Wilkinson, D. (2009) The Changing Sound of Music: Approaches to Studying Recorded Musical Performance (London: CHARM) http://www.charm.rhul.ac.uk/studies/chapters/intro.html

Lerdahl, F. \& Jackendoff, R. (1983). A Generative Theory of Tonal Music. Cambridge, MA: MIT Press.

Lindsay, K. A. \& Nordquist, P. R. (2007) More Than a Feeling: Some Technical Details of Swing Rhythm in Music. Acoustics Today, 3(3), 31-42.

London, J. (2012). Hearing in Time: Psychological Aspects of Musical Meter, second edition. Oxford: Oxford University Press.

Mermikides, M. (2010) Changes Over Time: Theory and Practice. Unpublished doctoral dissertation, University of Surrey, UK.

Moelants, D. (2006). Perception and performance of aksak metres. Musicae Scientiae, 10(2), 147-72.

Naveda, L., Gouyon, F., Guedes, C., \& Leman, M. (2011). Microtiming patterns and interactions with musical properties in Samba music. Journal of New Music Research, 40(3), 225-238.

Ohriner, M. S. (2012). Grouping hierarchy and trajectories of pacing in performances of Chopin's Mazurkas. Music Theory Online, 18(1).

Polak, R. (2010). Rhythmic feel as meter. Non-isochronous beat subdivision in jembe music from Mali. Music Theory Online, 16(4).

Polak, R., \& London, J. (2014). Timing and meter in Mande drumming from Mali. Music Theory Online 20(1).

Povel, D. J. (1984). A theoretical framework for rhythm perception. Psychological Research, 45(4), 31537.

Povel, D. J., \& Essens, P. (1985). Perception of temporal patterns. Music Perception, 2, 411-40.

Repp, B. H. (1997). Expressive timing in a Debussy prelude: A comparison of student and expert pianists. Musicae Scientiae, 1(2), 257-268.

Repp, B. H., London, J., \& Keller, P. E. (2011). Perception-production relationships and phase correction in synchronization with two-interval rhythms. Psychological Research, 75(3), 227-42.

Repp, B. H., London, J., \& Keller, P. E. (2012). Distortions in reproduction of two-interval rhythms: when the "attractor ratio" is not exactly 1: 2. Music Perception, 30(2), 205-23. 
Rice, T. (1994). May it fill your soul: Experiencing Bulgarian music. Chicago: University of Chicago Press.

Rice, T. (2000a). Béla Bartók and Bulgarian Rhythm. In Antokoletz, E., Fischer, V., \& Suchoff, B. (Eds.). Bartók Perspectives: Man, Composer, and Ethnomusicologist (pp. 196-210). Oxford: Oxford University Press.

Rice, T. (2000b) Bulgaria. In Rice, T., Porter, J., \& Goertzen, C. (Eds.) Garland Encyclopedia of World Music Volume 8 - Europe Part 3: Music Cultures of Europe. New York: Routledge.

Snyder, J. S., \& Large, E. W. (2005). Gamma-band activity reflects the metric structure of rhythmic tone sequences. Cognitive Brain Research, 24(1), 117-26.

Timmers, R., Endo, S., Bradbury, A., \& Wing, A. M. (2014). Synchronization and leadership in string quartet performance: a case study of auditory and visual cues. Frontiers in Psychology, 5.

Todd, N. P. (1985). A model of expressive timing in music. Music Perception, 3(1), 33-58.

Ullal-Gupta, S., Hannon, E. E., \& Snyder, J. S. (2014). Tapping to a Slow Tempo in the Presence of Simple and Complex Meters Reveals Experience-Specific Biases for Processing Music. PLoS ONE, 9(7).

Yeston, M. (1976). The stratification of musical rhythm. New Haven CT: Yale University Press. 